\title{
A EDUCAÇÃO FÍSICA NO ENSINO MÉDIO: UM OLHAR SOBRE O CORPO
}

\author{
PHYSICAL EDUCATION IN HIGH SCHOOL: FOCUS ON THE BODY
}

\author{
LA EDUCACIÓN FISICA EN LA ENSEÑANZA MEDIA: UNA MIRADA \\ SOBRE EL CUERPO
}

\author{
Fernanda Azevedo Gomes da Silva*, Luis Aureliano Imbiriba e Silva*, \\ Silvia Maria Agatti Lüdorf*
}

\section{Palavras-chave \\ Imagem corporal. \\ Educação Física.}

Estética.

Adolescente.

\begin{abstract}
Resumo: Os objetivos deste estudo são investigar e discutir quais aspectos relacionados ao corpo na contemporaneidade são destacados pelos professores, assim como verificar de que maneira seriam, eventualmente, abordados nas aulas de Educação Física do ensino médio de escolas do Rio de Janeiro. Os dados foram obtidos mediante aplicação de entrevista semiestruturada com 21 professores de diferentes instituições. Observouse que a aparência e a saúde sobressaíram como os aspectos mais valorizados no corpo. Essas temáticas parecem ser contempladas nas aulas de Educação Física no ensino médio, a partir de abordagens sobre práticas e hábitos relativos à saúde, à sexualidade e à diversidade corporal.
\end{abstract}

Abstract: The aims of this study were to investigate which aspects concerning to the body are stressed by teachers and to find out how they would be approached in high school Physical Education classes in Rio de Janeiro. Data were collected by semi-structured interviews with 21 teachers from distinct schools. Appearance and health were the most valued aspects concerning the body. These themes seem to appear in discussions about habits and practices related to health, sexuality and body diversity during high school physical education classes.

Resumen: Los objetivos de este estudio fueron investigar y discutir cuáles son los aspectos relacionados al cuerpo, en la contemporaneidad, que son destacados por los profesores, además de verificar de qué manera serían, eventualmente, abordados en las clases de Educación Física de la enseñanza media de escuelas de Rio de Janeiro. Los datos han sido obtenidos mediante entrevista semiestructurada realizada a 21 profesores de diferentes instituciones. Se detectó que la apariencia y la salud son los aspectos del cuerpo más valorados. Estas temáticas parecen ser contempladas en las clases de Educación Física en la enseñanza media a partir de abordajes sobre prácticas y hábitos relativos a la salud, la sexualidad y la diversidad corporal.
*Universidade Federal do Rio de Janeiro (UFRJ). Rio de Janeiro, RJ, Brasil.

E-mail: fernanda.ef@ig.com.br

Recebido em: 24-01-2015

Aprovado em: 07-04-2015 cc) (1) Creative Commom 


\section{INTRODUÇÃO}

Cada vez mais tem se discutido que o corpo, para além de sua dimensão biológica, é construído mediante sua inserção sociocultural e influenciado por dado processo histórico. Le Breton (2011) destaca a intensidade com que a cultura marca o corpo e suas práticas. Para Ortega (2008, p. 210): "Apesar de existirem invariantes estruturais e antropológicos da corporeidade humana, a não separação do corpo e do ambiente afirma a importância do meio social, cultural e histórico na experiência humana". Desta forma, as influências que os meios social, econômico e cultural exercem sobre as formas de o homem perceber o corpo, seu e do outro, possibilitam uma série de variações nas maneiras de se compreender e tratar o corpo.

O professor de Educação Física pode ser considerado um dos atores sociais que contribuem para a inscrição de sentidos e significados que historicamente permeiam o corpo (LÜDORF, 2008). No âmbito educacional, a Educação Física representa uma das disciplinas dedicadas a promover uma compreensão sobre valores e significados que estão implícitos nas práticas corporais presentes na sociedade.

De acordo com a literatura da área (SOARES et al., 1992, BRACHT, 1999; CASTELLANI FILHO, 2003, SOARES, 2004), o campo da Educação Física tem sofrido influências históricas que acabam por moldar as concepções de corpo que coexistem atualmente. Autores como Russo (2005) e Lüdorf (2010) enfatizam a necessidade de se repensar a disciplina Educação Física em âmbito educacional, levando em consideração questões relacionadas ao corpo na contemporaneidade, uma vez que temas como saúde, atividade física, cuidados corporais, estética, entre outros, têm recrudescido no campo de interesse dos jovens.

A insatisfação corporal na adolescência, por exemplo, constitui-se em tema que desperta cada vez mais interesse da comunidade científica. Damasceno et al. (2006), Conti et al. (2009), Matias et al. (2010), Palma et al. (2013), Fortes et al. (2013) detectaram níveis preocupantes de insatisfação corporal, principalmente entre as moças. Matias et al (2010) comentam que o olhar do adolescente sobre o próprio corpo deve ser tratado com atenção para que sejam evitados problemas posteriores, como distúrbios alimentares, bulimia, anorexia nervosa, obesidade e depressão. Maldonado (2006) e Palma et al. (2013) sugerem que a abordagem na Educação Física Escolar de temas que envolvam o padrão corporal vigente pode oportunizar a reflexão por parte dos jovens sobre o próprio corpo.

Documentos nacionais também defendem que assuntos relacionados ao corpo sejam abordados no ensino médio. Ainda que os Parâmetros Curriculares Nacionais para o ensino médio (BRASIL, 2000) não tenham destacado diretamente a necessidade de discutir corpo e padrões de corpo neste nível de ensino, as Orientações Curriculares Nacionais para o ensino médio (BRASIL, 2006) preconizam que o professor de Educação Física deve empreender discussões a este respeito.

Observa-se, então, a importância de se discutir, entre outros temas, aspectos relacionados à valorização da aparência do jovem, fase em que, segundo Assis et al. (2003) e Krayer, Ingledew e Iphofen (2008), ocorrem transições físicas, sexuais, cognitivas e emocionais. Além destas particularidades da adolescência, a sociedade atual voltada ao hiperconsumo, na visão de Lipovetski e Serroy (2013), promove o autodesregramento dos hábitos de vida e desorganização das condutas alimentares, ao mesmo tempo em que prega o modelo da 
magreza. Tais paradoxos convivem contemporaneamente, uma vez que a ideologia da saúde e da perfeição corporal leva a crer que os problemas de saúde derivam de falhas de caráter, falta de vontade ou, ainda, de fraqueza individual (ORTEGA, 2008).

Tais questões tornam-se preocupantes, sobretudo no que tange à adolescência, fase em que as preocupações com o corpo ganham magnitude em virtude das transformações associadas a ela. Assim, torna-se fundamental o papel dos professores de Educação Física, também, na problematização e discussão destes aspectos, como parte do processo formativo. No entanto, estudos voltados ao que o professor de Educação Física pensa sobre os aspectos que envolvem o corpo na contemporaneidade e, também, as formas de se tratá-los nas aulas, ainda são incipientes na literatura. Ainda que seja um tema atual e extremamente importante de ser discutido, raríssimas são as investigações relacionadas à Educação Física Escolar no ensino médio que destrincham as compreensões sobre a cultura somática vivenciada contemporaneamente.

Neste sentido, os objetivos deste estudo são investigar e discutir quais aspectos relacionados ao corpo na contemporaneidade são destacados pelos professores, assim como verificar de que maneira seriam, eventualmente, abordados nas aulas de Educação Física do ensino médio de escolas do Rio de Janeiro.

\section{DECISÕES METODOLÓGICAS}

Caracterizada principalmente pela profundidade de análise, a pesquisa de natureza qualitativa se preocupa basicamente com significados, opiniões e representações acerca de determinado fenômeno (TURATO, 2003). A presente investigação caracterizou-se pela utilização do enfoque interpretativo desde a coleta até a análise dos dados, bem como pela interação entre o pesquisado e o pesquisador, elemento essencial para a compreensão de determinadas questões de investigação (THOMAS; NELSON; SILVERMAN, 2007).

$\mathrm{Na}$ tentativa de conhecer as opiniões de professores de Educação Física de ensino médio no Rio de Janeiro, considerando-se a variabilidade em função de aspectos como localidade, tipo de escola (pública ou privada), gênero, entre outros, foi desenvolvida uma estratégia de acesso aos professores, descrita a seguir.

Em um primeiro momento foi solicitada autorização dos órgãos responsáveis (Secretaria Estadual de Educação - SEEDUC/ RJ, estabelecimentos federais e privados) envolvidos com as instituições escolares para a realização da pesquisa. Autorizado o acesso às unidades escolares, foram realizados contatos diretamente com as coordenadorias e setores responsáveis com o intuito de esclarecer sobre a investigação e obter indicações de professores de Educação Física atuantes no ensino médio das escolas. É importante mencionar que houve a preocupação em visitar escolas privadas e públicas da região metropolitana do Rio de Janeiro visando respeitar as possíveis diversidades sociais, econômicas e culturais existentes entre os bairros da Zona Sul, Zona Norte, Zona Oeste e Baixada Fluminense do Estado do Rio de Janeiro.

Em um segundo momento, os docentes que se enquadraram nos seguintes critérios: ser graduado(a) em Educação Física, atuar em escolas públicas e/ou privadas e lecionar em pelo menos uma turma do nível médio de ensino foram convidados a participar do estudo. 
Dos 21 professores ${ }^{1}$ que aceitaram participar da pesquisa, oito foram formados por instituições privadas e apenas quatro não possuíam nível de pós-graduação. Observa-se ainda a prevalência na participação de professores do sexo masculino (15 voluntários), conforme o quadro a seguir.

Quadro 1 - Perfil dos pesquisados

\begin{tabular}{|c|c|c|c|c|c|c|c|}
\hline \multirow[b]{2}{*}{ Professor } & \multirow[b]{2}{*}{ Sexo } & \multirow[b]{2}{*}{ Idade } & \multicolumn{2}{|c|}{ Pós-graduação } & \multirow[b]{2}{*}{ Escola } & \multirow{2}{*}{$\begin{array}{l}\text { Tempo de } \\
\text { docência } \\
\text { (anos) }\end{array}$} & \multirow[b]{2}{*}{ Região } \\
\hline & & & $\begin{array}{l}\text { Lato } \\
\text { Sensu }\end{array}$ & $\begin{array}{l}\text { Stricto } \\
\text { Sensu }\end{array}$ & & & \\
\hline $\mathrm{P} 1$ & M & 46 & $x$ & & Estadual & 25 & Zona Norte \\
\hline P2 & $M$ & 46 & $x$ & $x$ & Estadual & 8 & Zona Norte \\
\hline P3 & $M$ & 42 & $x$ & & Federal & 20 & Zona Sul \\
\hline P4 & $\mathrm{F}$ & 43 & $x$ & $x$ & Federal & 25 & Zona Sul \\
\hline P5 & $\mathrm{F}$ & 48 & $x$ & $x$ & Federal & 25 & Zona Sul \\
\hline P6 & M & 51 & $X$ & & Estadual & 26 & Zona Norte \\
\hline P7 & $\mathrm{F}$ & 29 & & & Particular & 3 & Zona Norte \\
\hline P8 & M & 25 & & & Particular & 1 & Baixada Fluminense \\
\hline P9 & $\mathrm{M}$ & 40 & $x$ & & Particular & 25 & Baixada Fluminense \\
\hline P10 & $M$ & 45 & $X$ & $x$ & Federal & 23 & Zona Sul \\
\hline $\mathrm{P} 11$ & $\mathrm{M}$ & 45 & & $x$ & Federal & 23 & Zona Norte \\
\hline P12 & $\mathrm{F}$ & 35 & $x$ & & Estadual & 10 & Zona Norte \\
\hline P13 & $\mathrm{F}$ & 59 & & & Particular & 34 & Zona Oeste \\
\hline P14 & $\mathrm{F}$ & 50 & $x$ & & Federal & 28 & Zona Sul \\
\hline P15 & $\mathrm{M}$ & 42 & & & Estadual & 21 & Zona Oeste \\
\hline P16 & $M$ & 37 & $x$ & & Estadual & 14 & Zona Norte \\
\hline P17 & $\mathrm{M}$ & 50 & $x$ & & Estadual & 29 & Zona Norte \\
\hline P18 & M & 49 & $x$ & & Particular & 25 & Zona Oeste \\
\hline P19 & $\mathrm{M}$ & 48 & $x$ & & Federal & 21 & Zona Norte \\
\hline $\mathrm{P} 20$ & $\mathrm{M}$ & 31 & $x$ & & Estadual & 10 & Baixada Fluminense \\
\hline $\mathrm{P} 21$ & $M$ & 46 & $x$ & & Estadual & 23 & Baixada Fluminense \\
\hline
\end{tabular}

Fonte: Elaborado pelos autores.

Foi utilizada a entrevista semiestruturada para obtenção do depoimento dos professores. Previamente houve o processo de validação do roteiro de questões ${ }^{2}$, com a participação de doutores especialistas na temática do estudo. Posteriormente, foi realizada uma pesquisa piloto para verificar a adequação do roteiro aos objetivos almejados.

O critério considerado no processo de seleção do número de entrevistados foi 0 princípio da "saturação", que determina a interrupção da inclusão de novos sujeitos no estudo mediante repetição de informações, isto é, a redução na variação dos dados (GASKELL, 2003).

O tratamento dos dados foi efetivado por meio da análise de conteúdo proposta por Turato (2003), baseada nos princípios de repetição (frequência com que determinado assunto é abordado) e de relevância (nem sempre mais citado, mas importante para o objetivo do estudo).

1 Na discussão dos dados, os 21 professores foram identificados por código alfanumérico (P1 a P21).

2 As questões abordadas no estudo foram: 1. Na sua opinião, que aspecto tem sido mais valorizado no corpo atualmente? 2. Você já teve oportunidade de discutir com seus alunos questões ligadas ao corpo? Que tipo de assunto foi discutido? Houve interesse por parte dos alunos? 3. Você acha que interfere na visão que os alunos têm ou deveriam ter do corpo? De que maneira? 4. Você notou em seus alunos algum comportamento de insatisfação ou descontentamento com o próprio corpo? Se este for o caso, o que você diria/disse a ele(a) se viesse pedir sua ajuda? 
A presente pesquisa foi aprovada pelo Comitê de Ética em Pesquisa do Instituto de Estudos de Saúde Coletiva da Universidade Federal do Rio de Janeiro (IESC/UFRJ) sob o parecer 09/2010. Os sujeitos participantes do presente estudo assinaram um Termo de Consentimento Livre e Esclarecido a fim de garantir o anonimato e o sigilo das informações cedidas.

\section{ANÁLISE E DISCUSSÃO DOS DADOS}

A partir dos dados coletados foi possível verificar que a aparência e a saúde sobressaem como os aspectos mais valorizados no corpo atualmente, segundo os professores entrevistados. De acordo com Le Breton (2011, p. 282): "A preocupação com a saúde e com a forma torna-se a pedra angular dos valores da Modernidade".

A valorização da aparência, que surge de maneira expressiva no discurso dos docentes, se refere às questões estritamente físicas e se relaciona à aparência ideal e à busca pelo corpo que é considerado belo:

[...] hoje em dia, se você não tem o corpo que está dentro dos "parâmetros normais" você se sente um pouco rejeitado, diferente, eu acho que existe essa preocupação sim, bastante [...]. (P5)

Na sociedade, o corpo é só visto como alguma coisa para ser exposta e para ser admirada [...] (P7)

Da mesma forma, observa-se que a aparência corporal surge como elemento importante para a inserção social. A partir do depoimento dos professores, sugere-se que há uma percepção do corpo como algo dissociado do homem, que precisa ser constantemente melhorado e cuidado, conforme já apontou Le Breton (2011).

Adicionalmente, nota-se a ideia de uma considerável influência dos padrões de corpo estabelecidos pelos meios de comunicação a respeito da imagem corporal a ser construída. Castro (2007) e Mahmud e Crittenden (2007) corroboram esta reflexão quando comentam que a mídia influencia as crenças que os indivíduos têm a respeito do próprio corpo e que aqueles que não compactuam com esse padrão de beleza podem ser desprezados ou estigmatizados pela sociedade. Para Goldenberg (2006), a beleza do corpo também constitui um ideal a ser perseguido pelos sujeitos na sociedade contemporânea.

Essa imposição social de modelo(s) de corpo padronizado(s) aparentemente definiria tipos de corpos que deverão ser desenvolvidos para obtenção de sucesso nas relações sociais, o que, de certo modo, é criticado pelos professores:

[...] a gente vive numa sociedade em que a cobrança de um corpo perfeito, especialmente os cariocas, que o povo vai à praia, o famoso que os meninos chamam de "teste da praia": vê quem está mais "gordinho", vê quem está mais "cheinho", isso é uma cobrança da sociedade [...] (P3)

[...] a questão de estética hoje em dia é muito valorizada; ser bonito, ser "sarado", estar bem, é valorizado até pelos meios de comunicação que impõem isso em nossa sociedade hoje. Eu acho que isso atinge bastante os jovens. (P8)

[...] aquele corpo "sarado", aquele modelo que a gente percebe que nos é imposto. Não só em programas relativos ao esporte, como de uma maneira em geral: novelas, filmes [...] (P20) 
A preocupação estética sob o ponto de vista da perfeição física tem sido tema de muitos estudos (GARCIA; LEMOS, 2003, GARCIA, 2005, KOWALSKI; FERREIRA, 2007, LACERDA, 2007, MENDES, 2009). Nesta perspectiva, percebe-se no discurso dos docentes uma aparente crítica à preocupação com a aparência evidenciada na atualidade. Isto se coaduna com o argumento de Lüdorf (2008) a respeito das imposições sociais de um padrão de beleza, que devem ser criticadas pelos professores de Educação Física em sua atuação profissional.

Desse modo, o culto ao corpo aparece como alvo de censura dos entrevistados à medida que em seus discursos negam, ou mencionam ironicamente, não compartilhar desta busca pelo corpo considerado perfeito. Por exemplo, pode-se citar a utilização de expressões como "sarado", "(abdome) tanquinho", "bumbum arrebitado", "cheinho", dentre outros. Diante deste panorama, é notório que os professores de Educação Física investigados possuem certo senso crítico quanto ao fenômeno do culto ao corpo.

Outro aspecto valorizado no corpo, segundo os professores, está relacionado à saúde, abordando as condições de estar e permanecer saudável:

[...] eu já noto que tem uma galerinha mais preocupada com essa coisa do aspecto saúde. Antigamente 0 aspecto saúde ficava com o cara que foi enviado pelo médico. [...] Hoje não, hoje já vão procurar mais (a atividade física) por uma questão de saúde. Então, aumentou um pouquinho mais (a busca pela saúde) e eu acho que isso aí já é um ganho pra gente. (P18)

Esses discursos geralmente vêm atrelados a uma busca pela saúde advinda de recomendação médica ou de outros hábitos relacionados. Portanto, observa-se que o ideal de saúde a ser perseguido emerge significativamente no discurso dos professores de forma positiva, havendo assim uma valorização social do desejo de estar ou se sentir saudável. Neste sentido, Bagrichevsky (2009) menciona que a saúde assume na atualidade o status de "estilo de vida", em que todos os comportamentos de risco devem ser evitados.

Entretanto, é possível perceber no discurso dos professores P14 e P18, por exemplo, que se encaixaram na presente categoria, uma necessidade de contrapor saúde a aparência, ou seja, a valorização da saúde geralmente aparece atrelada a uma desvalorização da aparência. Dessa forma, Castro (2007) argumenta que, geralmente, o cuidado com a saúde representa algo digno de orgulho, enquanto que uma preocupação essencialmente voltada à beleza física pode ser considerada fútil. Parece haver então maior aceitação social quando o "estar saudável" se sobrepõe ao "aparentar-se belo". Silva, Palma e Lüdorf (2013) também detectaram que os professores de Educação Física concebem muitas vezes a saúde como algo mais positivo do que a valorização da estética.

Cabe ressaltar também que o momento histórico/contexto em que se insere determinado ator social torna-se elemento fundamental no desenvolvimento de discussões que envolvem os aspectos mais valorizados no corpo atualmente. Os professores afirmam que a importância sobre o que se pensa hoje, sobre saúde, pode se comparar àquela promoção da beleza do corpo que há tempos era exaltada.

Assim, embora a valorização da aparência e a saúde tenham surgido no discurso dos professores como aspectos mais valorizados no corpo atualmente, as discussões tratadas no nível médio de ensino por estes mesmos docentes são diversificadas quando 0 assunto é 0 corpo. 
Surpreendente foi detectar que, quando indagados a respeito da existência de oportunidades para discussões relacionadas ao corpo com seus alunos do ensino médio, os docentes, com raríssimas exceções, afirmaram não fazer desses momentos uma prática atrelada ao planejamento do curso. Ao contrário, as discussões ocorrem apenas quando surgem situações no cotidiano das aulas, derivadas de assuntos levantados pela mídia, tais como anorexia, uso de anabolizantes, algum tipo de manifestação de insatisfação corporal ou dúvidas gerais envolvidas com a Educação Física que não partem de apenas um aluno. Ou seja, parece que tais fatores impulsionam, ocasionalmente apenas, debates sobre temáticas relativas ao corpo.

Quando ocorrem, o principal foco dessas conversas se situa em torno de práticas e hábitos relativos à saúde, ou seja, as discussões são voltadas à orientação dos professores envolvendo diversos comportamentos e atitudes que os alunos deveriam adotar no dia a dia, como pode ser visto nos trechos a seguir:

[...] eu procuro trazer problemas (para os alunos). Eu ainda pouco falei em anorexia, então agora com a morte dessa modelo que foi há pouco tempo e saiu em todas as manchetes de jornais, [...] procuro até trazer os problemas, falar com eles (alunos), tentar mostrar, eles vêm a mim. Eu tento deixar esse canal aberto (relação professor-aluno), eles vêm tirar dúvidas comigo. (P1)

[...] no início do ano agora, eles fizeram um trabalho sobre energia, sobre o consumo dos alimentos [...] aí eles fizeram uma pesquisa sobre os alimentos: quais são as vitaminas, as coisas boas e as coisas ruins que aquele alimento proporciona pra você, se você não comer ou se você comer em excesso, enfim, tentando fazer com que isso conscientizasse eles (alunos). (P7)

[...] a gente trabalha com [...] um livro que fala sobre atividade física relacionada a alguns casos específicos [...]: diabetes, osteoporose e tal, então a gente fala sobre tudo isso, e como eles são alunos de ensino médio [...] e estão muito preocupados com o vestibular, eles demonstram bastante interesse até pela proximidade que esses assuntos têm com a área de biologia. (P9)

Kunz (2007) sugere que a Educação Física se justifica principalmente através de ensinamentos que envolvem noções de saúde, o que, de acordo com Bracht et al. (2005), possivelmente afastaria os alunos de comportamentos ditos de risco. Para Devide (2003), é durante a fase escolar, isto é, ainda quando jovens, o momento ideal para a incorporação crítica de práticas e hábitos saudáveis visando uma vida adulta saudável.

Práticas como estar ativo fisicamente visando atenuar e/ou evitar doenças, ter cuidados com o corpo ao longo da vida, como a preocupação com a postura e uma alimentação equilibrada, são alguns exemplos de "estar saudável" que os professores mencionaram discutir em suas aulas com os alunos do ensino médio:

Eu tento passar que é importante para ele (aluno), principalmente que ele se prepare para que, se ele tem problema de peso [...] é importante que ele tenha consciência disso e tente resolver esse problema da melhor maneira possível para que ele consiga ter uma vida saudável. [...] Uma reeducação alimentar, uma reeducação postural, de atividade física [...]. (P1)

O que eu procuro indicar pra eles (alunos) é que eles devem se cuidar sempre, não só em um período do ano que é próximo do verão, eles devem ter uma atividade física regular. Se você estiver trabalhando a sua saúde, se você estiver sendo orientado corretamente [...] a estética vai acabar acontecendo naturalmente. (P3) 
Assim, é possível notar que a discussão sobre práticas e hábitos relativos à saúde no ensino médio se coaduna com a aparente percepção dos professores sobre os aspectos mais valorizados no corpo atualmente, conforme visto na discussão anterior sobre saúde. Dessa forma, os docentes tentam abordar, ainda que de forma não sistemática, temas presentes na contemporaneidade (magreza, obesidade, entre outros) em suas aulas, muitas vezes em uma perspectiva futura de cuidados após a vida escolar. Pode-se dizer que a preocupação crescente com a saúde pode levar os sujeitos a dedicar atenção cada vez maior ao seu corpo e a outras práticas que envolvem o seu ritmo de vida (LE BRETON, 2011).

Cabe ressaltar também que a ideia de estética do corpo é citada novamente para argumentar a favor da saúde. Isso se justifica, provavelmente, pelo fato de os professores mencionarem que a busca de um ideal de corpo pode ameaçar a saúde do jovem. As Orientações Curriculares Nacionais para o ensino médio (BRASIL, 2006) destacam que justamente um dos desafios da Educação Física em âmbito educacional neste nível de ensino é possibilitar que os jovens tornem-se críticos diante do exacerbado culto ao corpo.

Além disso, nota-se que a sexualidade emerge também como outra temática ligada ao corpo que tem sido abordada pelos professores no ensino médio:

[...] eu converso com eles (alunos) até sobre gravidez, sobre tudo, gravidez precoce, relação menino-menina [...] (P1)

[...] eles (alunos) falam muito da relação do corpo com namoro. ( 0 aluno diz:) "eu só quero namorar uma gatinha". A menina só quer namorar um cara "bonitinho", "fortinho", né, e isso é uma exigência, impressionante cara, isso é um tema central, entendeu? (P3)

[...] Eu normalmente explico pra eles (alunos) como eles têm que usar o seu corpo, eles têm que saber usar o corpo, inclusive até na parte sexual, a parte de higiene [...] eles têm [...] assuntos de sexo [...] obviamente que surge 0 assunto, mas eu não sou professora sexual né, de assunto sexual, mas a higiene de corpo leva a entender, inclusive estive explicando a eles a diferença do homem para a mulher, na parte, vamos dizer assim de corpo. (P13)

[...] eu dou um toque (aviso) sobre a sexualidade, porque o corpo deles está passando da fase da infância para a fase adulta. 0 corpo deles está modificando, então tem que dar um toque, o que pode, o que não pode, cada um tem a sua hora. (P15)

A ideia de sexualidade tratada na presente pesquisa se assemelha à perspectiva proposta por Prado e Ribeiro (2010, p. 409), ou seja: "[...] pode ser mais bem compreendida como uma junção (sobreposta) do biológico, das crenças, das ideologias, dos desejos, dos afetos das manifestações e práticas sexuais, fatores esses amplamente configurados por aspectos sociais e culturais". Neste sentido, busca-se ampliar o conceito para além da visão essencialmente biológica do corpo ligada ao sexo, pois, conforme Heilborn (2003) e Grossi (1998), a sexualidade pode se diferenciar em seus significados dentre os diversos grupos sociais.

Essa categoria abrange assuntos relacionados à sexualidade que são tratados pelos professores com seus alunos do ensino médio, tais como: gravidez precoce, relação sexual, higiene corporal, informações referentes às diferenças anatômicas entre os sexos, mudanças físicas da adolescência, além de discussões acerca de preconceitos ligados às opções sexuais.

Dessa maneira, muitas vezes a valorização corporal ressurge nos discursos dos professores como elemento importante nas relações afetivas entre os jovens e nota-se que 
a preocupação do aluno com a aparência cruza as questões referentes à sexualidade na medida em que a atração corporal se torna determinante nas relações interpessoais durante a puberdade.

Portanto, embora pareça que o professor de Educação Física tenha um importante papel no esclarecimento de questões que envolvam a sexualidade, como visto, trata-se mais de momentos informais e conversas individualizadas do que propriamente discussões em aula. Para Goellner (2010), abordar o tema sexualidade é favorecer a constituição da identidade dos sujeitos, neste caso, os alunos. Contudo, Prado e Ribeiro (2010) argumentam ser esse ainda um assunto pouco abordado na Educação Física Escolar.

Outra temática discutida com os alunos do ensino médio, segundo os professores, é a diversidade corporal:

[...] Veja bem, a gente conversa com os alunos no que é possível. [...] Então [...] quando surge algum conflito, quando a gente faz alguma atividade que surge algum conflito de gênero [...] ou então de bullying, do "gordinho", do "grandão", do "negro", do "dentuço", a gente aproveita esses momentos pra trabalhar essas contradições. [...] a gente tenta trabalhar na questão da afirmação, da melhoria da autoestima, trabalhando com eles a conscientização de um corpo, que eles têm corpos diferentes [...] (P10)

[...] qualquer erro que o colega cometa, na mesma hora vão ter três, quatro, cinco alunos que vão ali criticar esse colega. Vão dizer que ele jogou a bola fraco, deu o saque fraco, porque ele não tem força, não recebeu a bola porque ele é desajeitado, porque ele corre mal, porque ele não tem capacidade, porque ele é "baixinho". [...] Então a gente tem que parar e mostrar pra ele isso. [...] Então se meu aluno fala que ele é baixo e eu não aproveito esse momento pra estar discutindo com ele [...] muitas vezes eu paro a atividade, paro o jogo pra chamar a atenção do aluno sobre alguma coisa que ele falou do outro [...] a gente tem que parar, porque 0 aluno o tempo inteiro na Educação Física está se expondo. E muitas vezes o que eles têm medo é exatamente isso. (P17)

Observa-se no discurso dos professores a intenção de discutir durante as aulas de Educação Física no ensino médio questões que envolvam a aceitação do corpo (de si e do outro), o respeito às diferenças, sejam elas de ordem física, intelectual ou de habilidade, bem como desmistificar ideias preconcebidas socialmente que causam conflitos entre gêneros. Essa prática vai ao encontro da alteridade, princípio que abastece a perspectiva intercultural de educação proposta por Oliveira e Daolio (2010), voltada ao enfrentamento de preconceitos e sectarismos relativos à compreensão sobre a diversidade corporal.

Portanto, deve-se atentar para a importância dada ao corpo como meio de aceitação social observada anteriormente. 0 "tipo de corpo" parece definir um aspecto importante a ser discutido com jovens do ensino médio, na puberdade, cuja preocupação com o corpo pode ser considerada inerente às mudanças físicas comuns deste período da vida (DAMASCENO et al, 2006). Para Lüdorf (2008), ao trabalhar os valores inscritos no corpo e arraigados na cultura e também não ficando restrito apenas aos referenciais técnico-biológicos, o professor de Educação Física estaria praticando justamente os princípios que regem o que a autora denomina "educação sociocorporal".

Como pode ser visto, estereótipos como magro versus gordo, alto versus baixo, bonito versus feio, hábil versus inabilidoso, dentre outros, parecem ser palco de debate 
para o processo de ensino-aprendizagem da Educação Física no ensino médio ${ }^{3}$. Assim, o reducionismo em enxergar o "outro" apenas por suas características visíveis (atributos físicos de ideais puramente estéticos) que estigmatizam estereótipos pode ser tratado com os alunos por meio do diálogo sobre valores e atitudes referentes ao respeito à diferença (OLIVEIRA; DAOLIO, 2010).

\section{CONCLUSÕES}

Ao buscar compreender e discutir quais aspectos relacionados ao corpo na contemporaneidade são destacados pelos professores nas aulas de Educação Física do ensino médio, sob a ótica do próprio docente, foi identificado que a estética e a saúde sobressaem como os aspectos mais valorizados no corpo atualmente neste recorte da realidade escolar do Rio de Janeiro.

Dessa maneira, esses assuntos parecem permear as discussões sobre corpo que, ocasionalmente, são realizadas na disciplina de Educação Física em diferentes escolas. Além disso, algumas temáticas foram especialmente citadas, tais como práticas e hábitos relativos à saúde, à sexualidade e à diversidade corporal.

Embora esses assuntos sejam demandas da sociedade atual que merecem espaço nas aulas oferecidas pelo professor de Educação Física e de interesse dos alunos, e sejam, de certa forma, abordados pelos professores entrevistados, detectou-se que tais discussões não ocorrem de modo sistemático e tampouco fazem parte do planejamento da disciplina no ensino médio. Ao contrário, são tratados de modo informal ou ainda em conversas individualizadas.

Sugere-se, assim, que em estudos posteriores seja realizada uma investigação que abarque também observações de campo a fim de verificar a emergência de possíveis elementos que justifiquem, expliquem ou confirmem as relações entre os discursos obtidos e a efetiva prática educativa.

\section{REFERÊNCIAS}

ASSIS, Simone G. et al. A representação social do ser adolescente: um passo decisivo na promoção da saúde. Ciência \& Saúde Coletiva, Rio de Janeiro, v. 8, n. 3, p. 669-679, 2003.

BAGRICHEVSKY, Marcos. Del "cuerpo saludable" que se (des)constituye. Revista Brasileira de Ciências do Esporte, Campinas, v. 30, n. 3, p. 191-202, maio 2009.

BRACHT, Valter. A constituição das teorias pedagógicas da Educação Física. Caderno Cedes, Campinas, v. 19, n. 48, p. 69-88, ago. 1999.

BRACHT, Valter et al. Pesquisa em ação: educação física na escola. 2. ed. ljuí: Unijuí, 2005.

BRASIL. Ministério da Educação. Secretaria de Educação Básica. Orientações curriculares para o ensino médio: Linguagens, códigos e suas tecnologias. Brasília, 2006.

BRASIL. Ministério da Educação. Secretaria de Educação Média e Tecnológica. Parâmetros curriculares nacionais: ensino médio: linguagens, códigos e suas tecnologias. Brasília, 2000. 
CASTELLANI FILHO, Lino. Educação física no Brasil: a história que não se conta. 8. ed. Campinas: Papirus, 2003.

CASTRO, Ana Lucia de. Culto ao corpo e sociedade: mídia, estilos de vida e cultura de consumo. 2. ed. São Paulo: Annablume, 2007.

CONTI, Maria Aparecida et al. A insatisfação corporal de jovens: um estudo exploratório. Physis, Revista de Saúde Coletiva, Rio de Janeiro, v. 19, n. 2, p. 509-528, 2009.

DAMASCENO, Vinicius Oliveira et al. Imagem corporal e corpo ideal. Revista Brasileira de Ciência e Movimento, Brasília, v. 14, n. 1, p. 87-96, 2006.

DEVIDE, Fabiano Pries. A educação física escolar como via de educação para a saúde. In: BAGRICHEVSKY, Marcos; PALMA, Alexandre; ESTEVÃO, Adriana. (Org.). A saúde em debate na Educação Física. Blumenau: Edibes, 2003. p. 137-150.

FORTES, Leonardo de Souza et al. Insatisfação corporal em adolescentes: uma investigação longitudinal. Revista de Psiquiatria Clínica, São Paulo, v. 40, n. 5, p. 167-71, 2013.

GARCIA, Alessandro Barreta. Da estética privada, para uma estética pública: implicações na educação física do fetiche. Lecturas en Educación Física y Deportes, Buenos Aires, v. 10, n. 86, jul, 2005. Disponível em: <http://www.efdeportes.com>. Acesso em: 7 set. 2005.

GARCIA, Rui Proença; LEMOS, Katia Moreira. A estética como um valor na Educação Física. Revista Paulista de Educação Física, São Paulo, v. 17, n. 1, p. 32-40, jan./jun. 2003.

GASKELL, George. Entrevistas individuais e grupais. In: BAUER, Martin W.; GASKEL, George. (Ed.). Pesquisa qualitativa com texto, imagem e som: um manual prático. 2. ed. Petrópolis: Vozes, 2003. p. 64-89.

GOELLNER, Silvana Vilodre. A educação dos corpos, dos gêneros e das sexualidades e 0 reconhecimento da diversidade. Cadernos de Formação RBCE, Campinas, p. 71-83, 2010.

GOLDENBERG, Mirian. O corpo como capital: para compreender a cultura brasileira. Arquivos em Movimento, Rio de Janeiro, v. 2, n. 2, p. 115-123, jul./dez. 2006.

GONÇALVES, Maria Augusta Salin. Sentir, pensar, agir: corporeidade e educação. Campinas: Papirus. 1994.

GROSSI, Miriam Pillar. Identidade de gênero e sexualidade. Antropologia em Primeira Mão, Florianópolis, p. 1-18, 1998.

HEILBORN, Maria Luiza. Fronteiras simbólicas: gênero, corpo e sexualidade. Cepia, Rio de Janeiro, n. 5, p. 73-92, 2003.

KOWALSKI, Marizabel; FERREIRA, Maria Beatriz Rocha. Estética, corpo e cultura. Conexões, Campinas, v. 5, n. 2, p. 90-113, 2007.

KRAYER, A., INGLEDEW, D. K., IPHOFEN R. Social comparison and body image in adolescence: a grounded theory approach. Health Education Research, Oxford, v. 23, n. 5, p. 892-903, 2008.

KUNZ, Elenor. "Ministério da Saúde adverte: viver é prejudicial à saúde". In: BAGRICHEVSKY, Marcos; ESTEVÃO, Adriana; PALMA, Alexandre (Org.). A saúde em debate na Educação Física. Ilhéus: Editus, 2007. v. 3, p. 173-186. 
LACERDA, Teresa O. Uma aproximação estética ao corpo desportivo. Revista Portuguesa de Ciências do Desporto, Porto, v. 7, n. 3, p. 393-398, dez. 2007.

LE BRETON, David. Antropologia do corpo e modernidade. Tradução de Fábio dos Santos Creder Lopes. Petrópolis: Vozes, 2011.

LIPOVETSKY, Gilles; SERROY, Jean. A cultura-mundo: resposta a uma sociedade desorientada. Tradução de Maria Lúcia Machado. São Paulo: Companhia das Letras, 2013.

LÜDORF, Silvia Maria Agatti. Formação de professores de educação física: retratos de uma instituição. Revista Brasileira de Docência, Ensino e Pesquisa em Educação Física, Goiás, v. 2, n. 1, p. 126-136, jul. 2010.

LÜDORF, Silvia Maria Agatti. Refletindo sobre o corpo design e a formação de professores de Educação Física: por uma educação sociocorporal. In: ROMERO, Elaine; PEREIRA, Erick Giuseppe B. (Org.). Universo do corpo: masculinidades e feminilidades. Rio de Janeiro: Shape, 2008. p. 60-83.

MAHMUD, Nargis, CRITTENDEN, Nadia. A comparative study of body image of Australian and Pakistani young females. British Journal of Psychology, London, v. 98, n. 2, p. 187-197, 2007.

MALDONADO, Gisela de Rosso. A Educação Física e o adolescente: a imagem corporal e a estética da transformação na mídia impressa. Revista Mackenzie de Educação Física e Esporte, São Paulo, v. 5, n. 1, p. 59-76, 2006.

MATIAS, Thiago Sousa et al. Satisfação corporal associada a prática de atividade física na adolescência. Motriz, Rio Claro, v. 16, n. 2, p. 370-378, abr./jun. 2010.

MENDES, Maria Isabel Brandão de Souza. Do ideal de robustez ao ideal de magreza: educação física, saúde e estética. Movimento, Porto Alegre, v. 15, n. 4, p. 174-191, out./dez. 2009.

OLIVEIRA, Rogério Cruz de; DAOLIO, Jocimar. Educação Física, cultura e escola: da diferença como desigualdade à alteridade como possibilidade. Movimento, Porto Alegre, v. 16, n. 1, p. 149-167, jan./mar. 2010.

ORTEGA, Francisco. 0 corpo incerto: corporeidade, tecnologias médicas e cultura contemporânea. Rio de Janeiro: Garamond, 2008.

PALMA, Alexandre et al. Insatisfação com o peso e a massa corporal em estudantes do ensino fundamental e médio do sexo feminino no município do Rio de Janeiro. Revista Brasileira de Ciências do Esporte, Florianópolis, v. 35, n. 1, p. 51-64, jan./mar. 2013.

PRADO, Vagner Matias do; RIBEIRO, Arilda Inês Miranda. Gêneros, sexualidades e Educação Física escolar: um início de conversa. Motriz, Rio Claro, v. 16, n. 2, p. 402-413, abr./jun. 2010.

RUSSO, Renata. Imagem corporal: construção através da cultura do belo. Movimento \& Percepção, São Paulo, v. 5, n. 6, p. 80-90, jan.jun. 2005.

SILVA, Alan Camargo; PALMA, Alexandre; LÜDORF, Sílvia Maria Agatti. O envelhecimento do professor de Educação Física e sua prática profissional: significados atribuídos ao corpo e à saúde. Pensar a Prática, Goiânia, v.16, n. 3, p. 817- 833, jul./set. 2013.

SILVA, Alan Camargo; LÜDORF, Sílvia Maria Agatti. Possíveis relações entre corpo, saúde e o envelhecimento do professor de Educação Física. Movimento, Porto Alegre, v. 18, p. 187-204, 2012. 
SOARES, Carmen Lúcia. Educação física: raízes européias e Brasil. 3. ed. Campinas: Autores Associados, 2004.

SOARES, Carmen Lúcia et al. Metodologia do ensino de educação física. São Paulo: Cortez, 1992.

THOMAS, Jerry R.; NELSON, Jack K.; SILVERMAN, Stephen J. Métodos de pesquisa em atividade física. 5. ed. Porto Alegre: Artmed, 2007.

TURATO, Egberto Ribeiro. Tratado da metodologia da pesquisa clínico-qualitativa: construção teórico-epistemológica, discussão comparada e aplicação nas áreas da saúde e humanas. 2. ed. Petrópolis: Vozes, 2003. 